Check for updates

Cite this: RSC Adv., 2019, 9, 26996

Received 25th July 2019

Accepted 16th August 2019

DOI: $10.1039 / c 9 r a 05751$

rsc.li/rsc-advances

\title{
Evolution of the phases and the polishing performance of ceria-based compounds synthesized by a facile calcination method
}

\author{
Wenli Pei, ${ }^{\text {*a }}$ Dong Zhao, (iD) ${ }^{a}$ Xianghui Chen, ${ }^{\text {*ab }}$ Xiaoyang Wang, ${ }^{c}$ Xingbo Yang, ${ }^{d}$ \\ Jianjun Wang, ${ }^{a}$ Zhijie Li ${ }^{b}$ and Lihu Zhou ${ }^{\mathrm{b}}$
}

Ceria-based compounds with additions of La and F (CLF compounds) were prepared by using industrialgrade fluorinated lanthanum cerium carbonate as a precursor via a facile calcination method. The evolution of phase structures of the compounds during preparation and the relationship between the structure and the polishing performance were investigated. The compounds consist of three phases: $\mathrm{CeO}_{2}, \mathrm{LaOF}$, and $\mathrm{LaF}_{3}$. The phase component could be controlled by tuning the calcination process. A higher degree of fluorination and a higher calcination temperature led to the formation of more LaOF and less $\mathrm{LaF}_{3}$ phases. The LaOF phase performs a higher stock removal rate. The best polishing efficiency was achieved with LaOF phase ratio around $18 \%$. Intermetallic $\mathrm{LaF}_{3}$ is a low-hardness phase and is easily crushed during polishing, which lowers the removal rate and shortens the useful life of the polishing powder.

\section{Introduction}

In recent years, ceria-based compounds have been paid considerable attention for their potential applications in emerging technologies in environmental and energy related applications..$^{1-4}$ It is widely used as various silica-containing glass materials because of their unique mechanical and chemical polishing performance..$^{5-8}$ Usually, the cutting efficiency of pure $\mathrm{CeO}_{2}$ is lower than that of ceria-based compounds added with La. ${ }^{9-11}$ With the development of the precision optics industry and the emergence of new applications, the requirements for a neat finish of the glass surfaces are getting more stringent. As a result, rare earth polishing compounds with the addition of La are getting more attention in the market. ${ }^{12,13}$

Ceria-based polishing materials are fluorinated during the preparation of the precursors, which results in the formation of new phases in the final products. ${ }^{14,15}$ These phrases play an important role in determining the hardness, the crystal structure, and the morphology of the polishing particles, which in turn influences the polishing performance. Fluorine can form two phases, namely LaOF and $\mathrm{LaF}_{3}$, in the ceria matrix and

\footnotetext{
${ }^{a}$ Key Laboratory for Anisotropy and Texture of Materials, College of Materials Science and Engineering, Northeastern University, Shenyang 110819, China. E-mail: peiwl@ atm.neu.edu.cn; xianghuio205@163.com

${ }^{b}$ Demeter (Suzhou) Electronic Environmental Protection Material Co., Ltd., Suzhou 215000, China

'Key Laboratory of Electromagnetic Processing of Materials, School of Metallurgy, Northeastern University, Shenyang 110819, China

${ }^{d}$ Demeter Technologies Inc., Burlingame, CA 94010, USA
}

a small number of $\mathrm{F}$ atoms dissolve in the lattice of ceria. ${ }^{16,17}$ The $\mathrm{F}$ atoms can significantly improve the chemical activity of ceria in the polishing process as well as enhance its polishing performance. ${ }^{18,19}$ Therefore, ceria-based compounds added with La and F (CLF compounds) have gained much interest and became promising polishing materials. Previous studies showed that the behavior of the $\mathrm{F}$ atoms and the phase structures including the formation and the distribution of $\mathrm{CeO}_{2}$, $\mathrm{LaOF}$, and $\mathrm{LaF}_{3}$, are closely related to the polishing performance. ${ }^{20,21}$ However, it is still not clear how to control the phase components in the ceria-based polishing powders. More importantly, there are few reports on what role the phases play on the polishing performance..$^{22,23}$

In this work, the evolution of the structure of the CLF compounds during preparation and the relationship between the structures and the polishing performance were subsequently investigated. The influence of the phase components and the role of the different phases on the polishing process were discussed. In addition, the preparation method of the $R_{\mathrm{a}}$ compounds polishing powder was optimized. The work provides an insight into the mechanism that La and F improve the polishing performance, and set out fundamental guidelines for the preparation of CLF compounds with an optimal polishing performance.

\section{Experimental procedure}

\section{Preparation of the CLF compound powders}

Industrial-grade cerium lanthanum carbonate was added into a reactor containing a given volume of deionized water to obtain 
a mixture with a solid content of $50 \%$. Then, the mixture was then stirred for $30 \mathrm{~min}$ to obtain a solution and different amounts of $\mathrm{HF}(30 \%)$ were added. After $2 \mathrm{~h}$ reaction at $80{ }^{\circ} \mathrm{C}$, a $0.5 \mathrm{~mol} \mathrm{~L}^{-1} \mathrm{NH}_{4} \mathrm{HCO}_{3}$ solution was gradually added until the precipitation was complete. The prepared mixture was then filtered, washed, and dried at room temperature to obtain the precursor materials with different fluorine contents. All precursor materials were milled to obtain a smaller particle size with a similar particle size distribution (PSD) via a ball-milling process. The precursor materials were then calcined in a muffle furnace to obtain the final CLF compound powders.

\section{Characterization}

The particle size distribution (PSD) of the polishing powders was measured using a laser particle size analyzer (Malvern 2000E) and the specific surface area (SSA) of the polishing powder was measured with a BET system (H300-2000A). The crystal structures were determined by X-ray Diffraction (XRD) on an X'Pert Powder 003 system. The morphology and the microstructures were analyzed by transmission electron microscopy (TEM) on a JEOL JEM-2100F system. The polishing performance was checked by using a 9B polisher to work on the normal commercial $\mathrm{K} 9$ glass. The surface roughness of the polished glass was evaluated by an EDGE QQAFM-01 atomic force microscope (AFM).

\section{Results and discussion}

\section{Influence of the $\mathrm{F}$ content on the CLF compound powders}

The precursors with a fluorine content of $2 \%, 5 \%$, and $10 \%$ were calcined from 800 to $1000{ }^{\circ} \mathrm{C}$ for $3 \mathrm{~h}$. The average particle size of the samples was measured and summarized in Fig. 1. Normally, the particle size increases with the calcination temperature. The fluorine content significantly influenced the particle size. For the same calcination temperature, the highest fluorine content resulted in the larger particles.

The TEM micrographs of the samples with a fluorine content of $2 \%, 5 \%$, and $10 \%$ obtained at $950{ }^{\circ} \mathrm{C}$ for $3 \mathrm{~h}$ are shown in Fig. 2. Higher fluorine contents result in larger particles for the

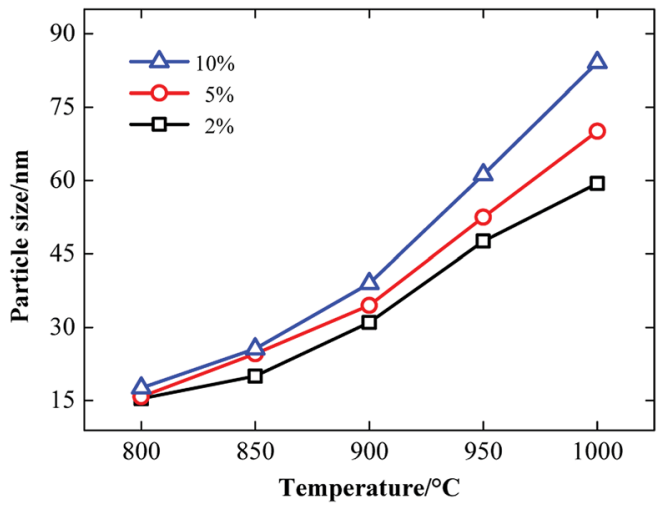

Fig. 1 Dependence of the average particle size on the calcination temperature for different samples with the fluorine content of $2 \%, 5 \%$, and $10 \%$.

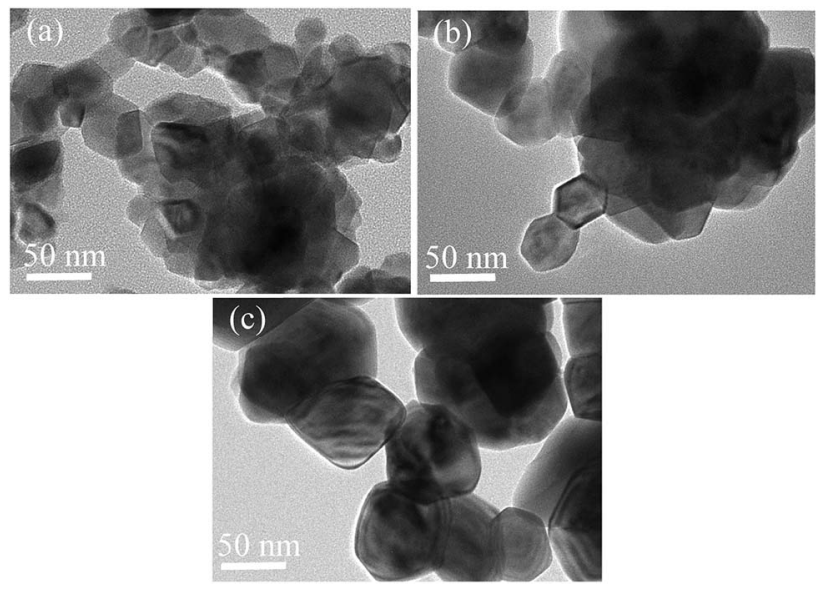

Fig. 2 TEM micrographs of the samples with different fluorine contents of (a) $2 \%$, (b) $5 \%$, and (c) $10 \%$.

same calcination temperature, which agrees with the results from the laser analyzer. The particles with the lowest fluorine content of $2 \%$ are agglomerated. The agglomerate is composed of smaller particles with an irregular polygonal shape, which indicates that the crystallization degree of the particles is lower. When the fluorine content increases, the particles adopt a hexagon-like morphology and present a higher crystallization degree. The addition of the more $\mathrm{F}$ atoms benefits crystal growth. The particles with a higher fluorine content present a more sufficient crystallization degree.

\section{Evolution of the phases of the CLF compounds}

The cerium lanthanum precursors with $0 \%, 2 \%, 5 \%$, and $10 \%$ fluorine were calcined at $950{ }^{\circ} \mathrm{C}$ for 3 h. Fig. 3 shows the XRD diffraction patterns of the samples for which the diffraction peaks of $\mathrm{CeO}_{2}, \mathrm{LaOF}$, and $\mathrm{LaF}_{3}$ could be indexed. The $\mathrm{La}_{2} \mathrm{O}_{3}$ phase was not observed in the XRD pattern, which indicates that both $\mathrm{La}$ and $\mathrm{F}$ atoms dissolved into the $\mathrm{CeO}_{2}$ lattice of the cubic fluorite structure. The characteristic peak for $\mathrm{CeO}_{2}$ shifted to lower angles with the increasing $\mathrm{F}$ content. This is because the solid solution of La atoms and a large number of $\mathrm{F}$ atoms

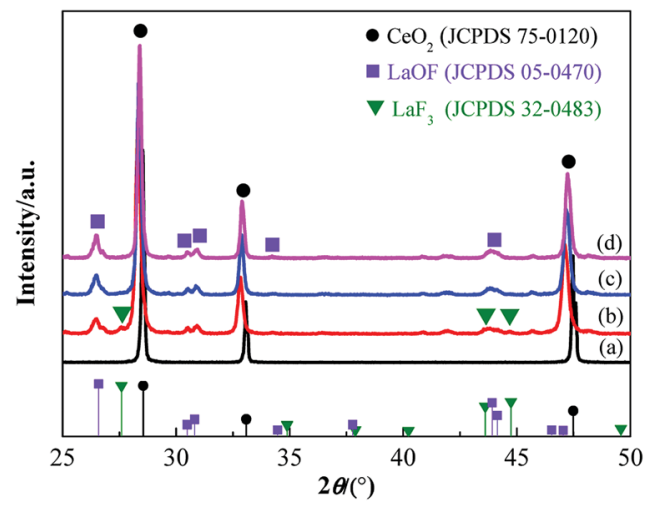

Fig. 3 XRD patterns of the ceria compound with different fluorine contents from (a) $0 \%$, (b) $2 \%$, (c) $5 \%$, and (d) $10 \%$. 
increases the inter-planar spacing of $\mathrm{CeO}_{2}$, which results in a shift of the characteristic peak. Noticeably, the component of the phases in the samples with different fluorine contents is diverse. The diffraction patterns were analyzed using the X'Pert HighScore software to calculate the phase component of the samples. Fig. 4 lists the proportion of different crystal phases in the samples with different fluorine contents.

The proportion of the $\mathrm{LaF}_{3}$ phase decreases and the LaOF phase increases when the $\mathrm{F}$ content increases. A La atom is larger than a Ce atom. When the La atoms replace the Ce atoms in the structure, the lattice is distorted and defects are caused near the area where the La atom entered the lattice. $\mathrm{F}$ atoms have a small size and are likely to occupy the lattice of highenergy defects and form LaOF to reduce the density of defects and form a more sufficient crystallization degree. The more $\mathrm{F}$ atoms dissolve into the $\mathrm{CeO}_{2}$ phase doped by $\mathrm{La}$, the more $\mathrm{LaOF}$ can be obtained. Therefore, controlling the fluorine content is an efficient way to tune the phase component in our method. Fig. 5 shows the particle size of the CLF compounds has a close relationship with LaOF content. The particle size grows up with the increase of LaOF content, which means the more F content can facilitate the particle growth.

Fig. 6 shows the XRD patterns of a sample prepared by calcinating the precursor with a fluorine content of $10 \%$ from $800{ }^{\circ} \mathrm{C}$ to $950{ }^{\circ} \mathrm{C}$. The intensity of the diffraction peaks increased and the half-width of the diffraction peaks decreased with the increasing calcination temperature. It indicates that a higher calcination temperature results in a more sufficient crystallization degree and a larger grain size in the CLF compound powders. The $\mathrm{LaF}_{3}$ phase was found in the samples obtained at a lower temperature but was no longer present for a temperature above $900{ }^{\circ} \mathrm{C}$. Therefore, a high enough temperature can avoid the presence of the $\mathrm{LaF}_{3}$ phase in the product.

Fig. 7 demonstrates a comparison of the infrared spectroscopy results for pure ceria and the CLF compounds with an $\mathrm{F}$ content of $5 \%$ prepared by calcination at $800{ }^{\circ} \mathrm{C}$ and $1000{ }^{\circ} \mathrm{C}$. In the figure, the peaks at $478.92 \mathrm{~cm}^{-1}$ and $1241.40 \mathrm{~cm}^{-1}$ are due to the stretching vibration of $\mathrm{Ce}-\mathrm{O}$. The stretching vibration of the La-F bond appears near $1123.10 \mathrm{~cm}^{-1}$ and that of $\mathrm{F}-\mathrm{O}$ is around $1048.74 \mathrm{~cm}^{-1}$. The infrared spectrum of the calcined

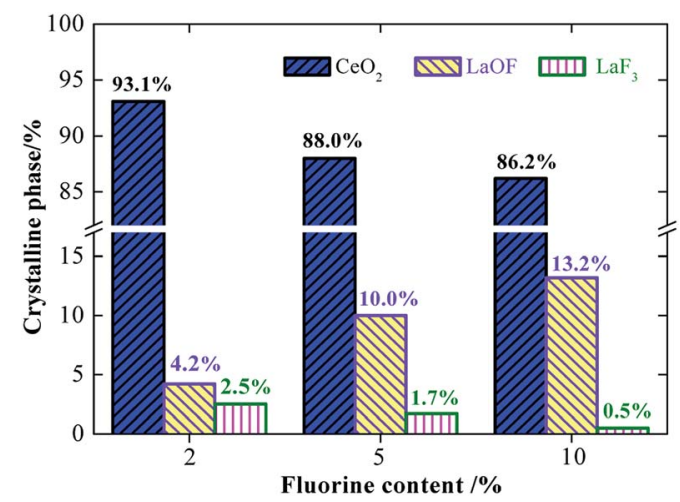

Fig. 4 Phase component of the CLF compounds with different fluorine contents.

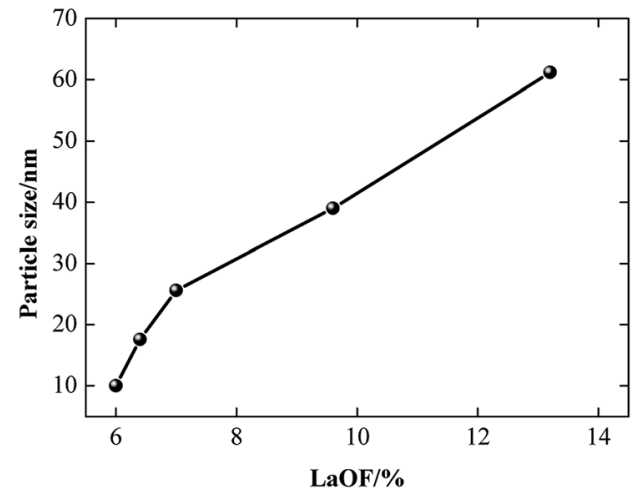

Fig. 5 The relationship between LaOF phase content and the particle size.

product of fluorocarbonate also shows the vibration peak of $\mathrm{Ce}-$ O. In addition, the vibration peaks of $\mathrm{La}-\mathrm{F}$ and $\mathrm{F}-\mathrm{O}$ also appeared in the calcined fluorocarbonate. The presence of $\mathrm{LaF}_{3}$ and LaOF compounds was also demonstrated, indicating that the $\mathrm{La}$ and $\mathrm{F}$ atoms are doped into the crystal lattice of $\mathrm{CeO}_{2}$ and precipitate to form $\mathrm{LaF}_{3}$ and LaOF phases.

\section{Evaluation of the polishing performance}

Cerium-based polishing powders with different phase ratios were obtained by adjusting the fluorine content. The powders were mixed with water to form an aqueous slurry with $10 \%$ solid content to polish the $\mathrm{K} 9$ glass on a 9B polisher with a polishing mat. The polishing time was fixed at $30 \mathrm{~min}$ with a polishing pressure of $20 \mathrm{kPa}$, along with a rotation speed of the plates of $30 \mathrm{rpm}$ and a slurry flow rate of $1000 \mathrm{ml} \mathrm{min}^{-1}$. The material removal rate is defined by the change in the mass of the glass substrates before and after polishing.

Fig. 8 shows the dependence of the material removal rate (MRR) and the average roughness $\left(R_{\mathrm{a}}\right)$ of the glass surface on the percentage of LaOF phase in the matrix of the polishing powder. As shown in Fig. 8, the MRR increases with the LaOF phase

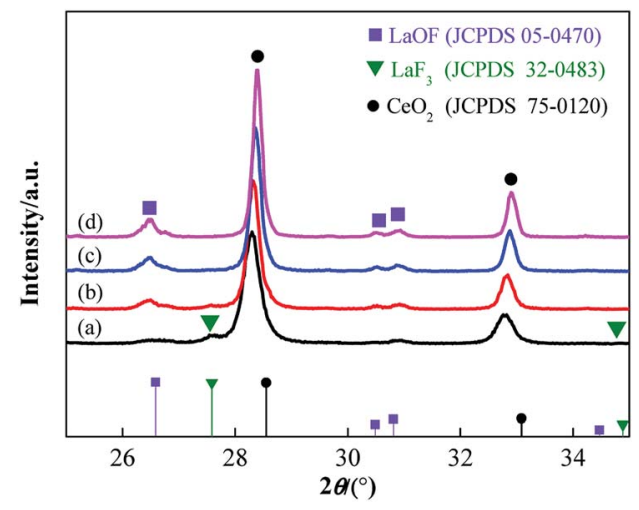

Fig. 6 XRD patterns of the samples with a precursor material containing $10 \%$ fluorine content calcined at different temperatures, from (a) $800^{\circ} \mathrm{C}$, (b) $850{ }^{\circ} \mathrm{C}$, (c) $900^{\circ} \mathrm{C}$, and (d) $950{ }^{\circ} \mathrm{C}$. 


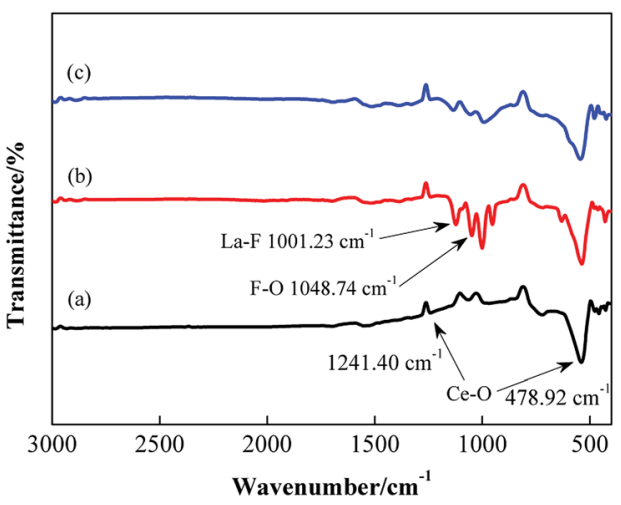

Fig. 7 The infrared spectra of pure ceria powder calcinated at (a) $800{ }^{\circ} \mathrm{C}$, and the CLF compounds powder with $5 \% \mathrm{~F}$ calcinated at (b) $1000^{\circ} \mathrm{C}$ and (c) $800^{\circ} \mathrm{C}$.

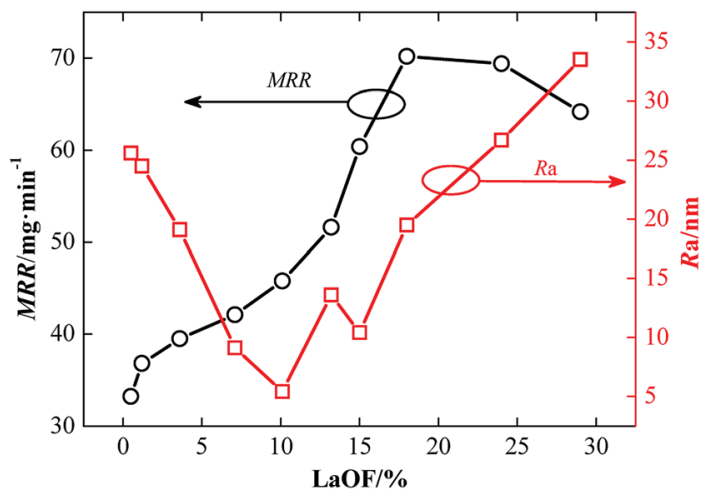

Fig. 8 Dependence of the material removal rate (MRR) and the surface roughness $\left(R_{\mathrm{a}}\right)$ on the percentage of LaOF phase in the matrix of the polishing powder.

ratio, saturates around 18\% LaOF phase ratio, then decreases. The best $R_{\mathrm{a}}$ was achieved around a $10 \% \mathrm{LaOF}$ phase ratio.

According to the Cook theory, ${ }^{24} \mathrm{CeO}_{2}$ is the main functional component of ceria-based compounds for polishing $\mathrm{SiO}_{2}$-containing glass. During glass polishing, two functional processes are taking place: the mechanical grinding and the chemical action of $\mathrm{Ce}^{4+}$ in the slurry solution on $\mathrm{SiO}_{2}$. The LaOF crystal phase of the ceria-based polishing powder with high fluorine content increases the hardness of the polishing particles and enhance the effect of mechanical polishing on the glass surface. At the same time, the presence of the LaOF phase causes more distortion in the lattice, which increases the energy and narrows the energy band gap of $\mathrm{Ce}^{4+}$. As a result, the chemical reaction of $\mathrm{Ce}^{4+}$ with $\mathrm{SiO}_{2}$ is enhanced by the higher distorted energy field. The hardness and the integrity of the polishing particles/grains grow further when the LaOF phase ratio is over $18 \%$, which increases the particle size and reduces the contact area with the polished glass surface to lower the MRR.

When the phase ratio of LaOF is low, the effect of mechanical polishing is not enough to remove the grinding marks that come from the previous step. For this reason, the surface roughness of the glass is higher. A further increase in the phase ratio of LaOF enhances both the mechanical and chemical polishing actions. The surface quality of the glass is optimal for a $10 \%$ LaOF phase ratio. When the phase ratio of LaOF increases further, the increased hardness of the polishing particles will add more scratches to the surface of the polished glass and $R_{\mathrm{a}}$ increases.

The surface roughness was measured by using AFM. The AFM patterns presented the different height difference by using color contrast, and the highest value and the lowest value could be obtained by using the AFM software. In this work, the average height difference between the highest zone was calculated as the surface roughness. The 2D and 3D AFM scans of K9 glass before (Fig. 9a and c) and after (Fig. 9b and d) polishing by $10 \%$ LaOF polished powder are shown in Fig. 9. It can be found that the surface roughness is $34.8 \mathrm{~nm}$, but drops to $5.4 \mathrm{~nm}$ after polishing, which significantly improves the surface quality and meets the surface quality requirements for optical glass. The $\mathrm{LaF}_{3}$ phase is maintained at a low percentage level, which indicates that the $\mathrm{F}$ and $\mathrm{La}$ atoms are more likely to form a LaOF phase in the $\mathrm{CeO}_{2}$ matrix and lower the free energy. Fig. 10 shows the HRTEM micrographs of the samples with different $\mathrm{F}$ content obtained at different temperatures. The insets in (a) and (c) are the morphology of the samples calcined at $800{ }^{\circ} \mathrm{C}$ and $900{ }^{\circ} \mathrm{C}$, respectively. The dash lines separate the different phases. As shown in Fig. 10, $\mathrm{LaF}_{3}$ is an intermetallic phase precipitated in the main matrix. The Mohs hardness of the intergranular $\mathrm{LaF}_{3}$ precipitate is 4.5 while the Mohs hardness of $\mathrm{CeO}_{2}$ is about 7.0 and that of the ceria-based rare earth polishing powder is higher than 7.0 because the La and $\mathrm{F}$ atoms dissolve into the matrix phases to strengthen the solution. ${ }^{25}$
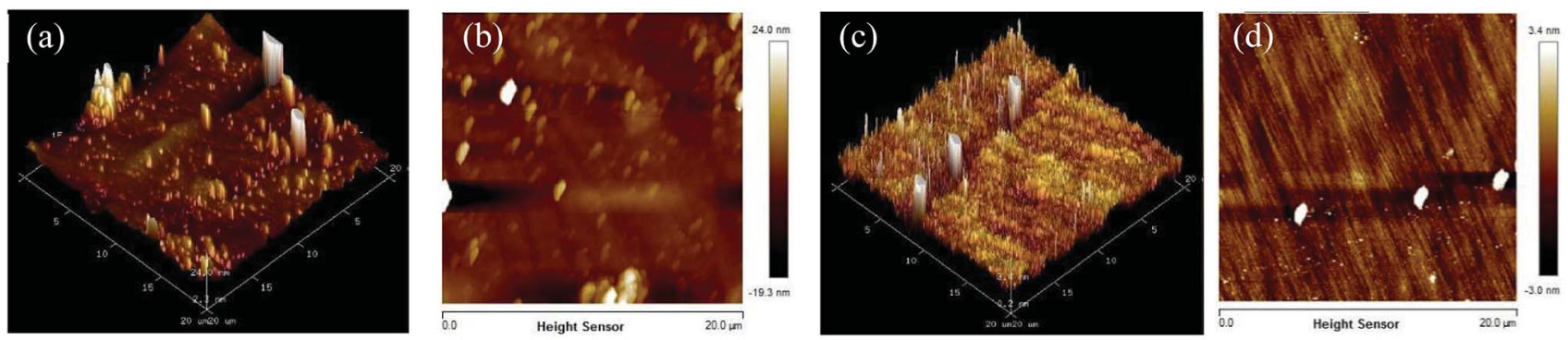

Fig. 9 Atomic force microscopy (AFM) 2D and 3D images of the $\mathrm{K} 9$ glass surface: ( $a$ and b) before polishing, and (c and d) after polishing. 

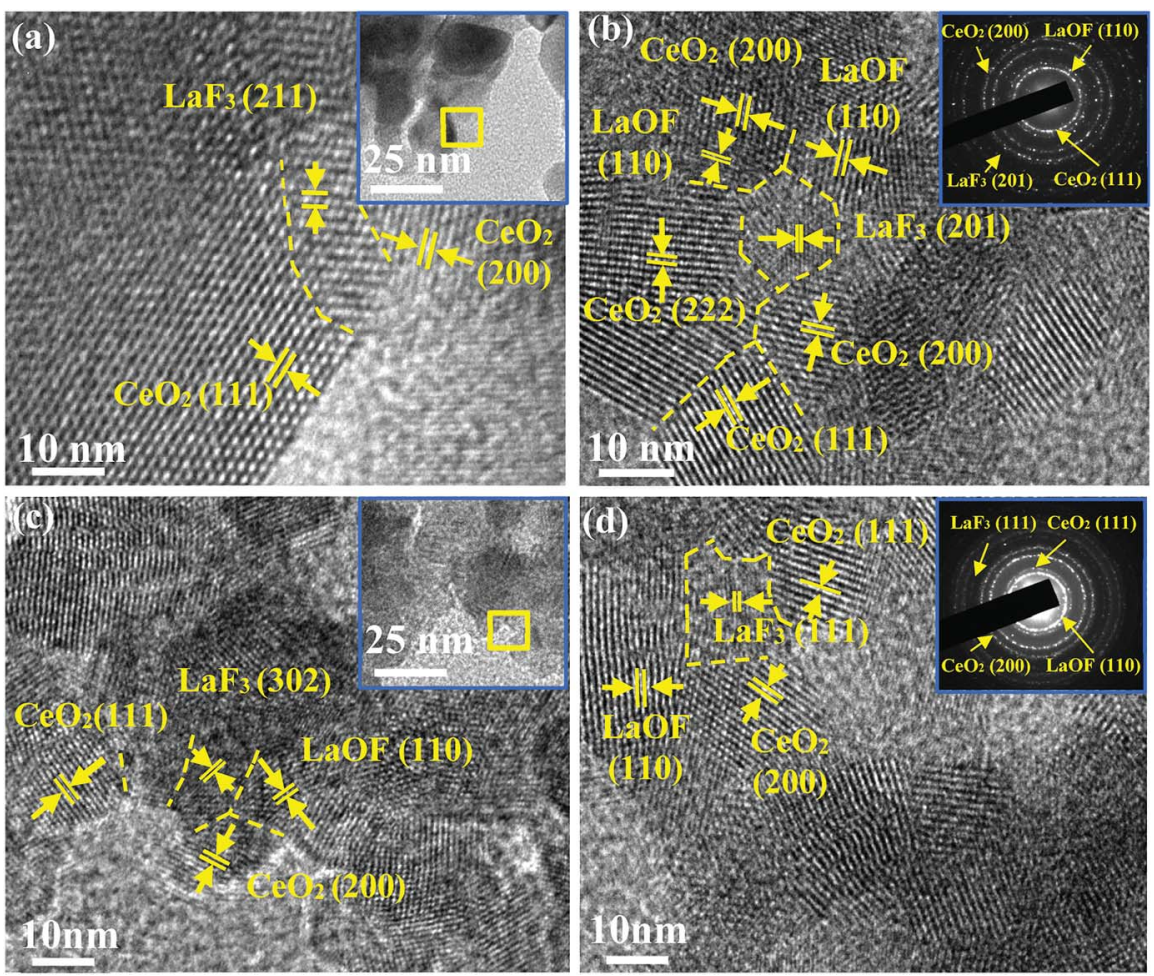

Fig. $10 \mathrm{HRTEM}$ of the matrix lattice of the $\mathrm{CeO}_{2}$ compounds with (a) $2 \% \mathrm{~F}$ calcined at $800{ }^{\circ} \mathrm{C}$, (b) $5 \% \mathrm{~F}$ calcined at $800{ }^{\circ} \mathrm{C}$ (c) $2 \% \mathrm{~F}$ calcined at $900{ }^{\circ} \mathrm{C}$, (d) $5 \% \mathrm{~F}$ calcined at $900{ }^{\circ} \mathrm{C}$. The inset figure in (a) and (c) are TEM images, and the inset figure in (b) and (d) are SAED.

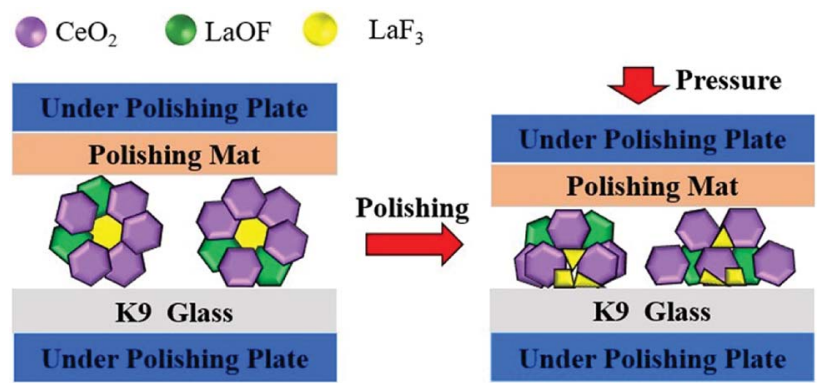

Fig. 11 Schematic of the action of the particles during polishing

As sketched in Fig. 11, the stress is easily concentrated around $\mathrm{LaF}_{3}$ phase due to the pressure during polishing, which causes a com-pressive force between the particles and the glass surface to cause a fraction of the $\mathrm{LaF}_{3}$ phase, and thus the particle, to break. This lowers the polishing performance of the particles. Therefore, the $\mathrm{LaF}_{3}$ phase is damaging to the fluorinecontaining ceria-based polishing powder particles. The presence of the $\mathrm{LaF}_{3}$ phase in the polishing compound must therefore be reduced to extend the polishing life of the powder. According to the data in Fig. 4, the ratio of LaOF can be controlled by adjusting the degree of fluorination in the precursor material or by formulating a more reasonable calcination process. In addition, when formulating the calcination process, the ratio of the harmful phase $\mathrm{LaF}_{3}$ can be reduced by increasing the calcination temperature or prolonging the holding time.

\section{Conclusion}

In summary, CLF compound polishing powders were prepared by a facile calcination method. The compounds are composed of three phases: $\mathrm{CeO}_{2}, \mathrm{LaOF}$, and $\mathrm{LaF}_{3}$. The investigation of the evolution of the phrase indicates that the phase component of the CLF compounds can be controlled by tuning the fluorine content of the precursor and increasing the calcination temperature. The $\mathrm{LaF}_{3}$ phase is an intermetallic compound precipitated in the main compound matrix. The polishing particles with more $\mathrm{LaF}_{3}$ phase are prone to cracking during polishing, which can deteriorate the MRR. The $\mathrm{LaF}_{3}$ phase is responsible for shortening the polishing lifetime of the CLF compounds. The LaOF phase improves the polishing performance. The LaOF phase in the $\mathrm{CeO}_{2}$ matrix lattice has the highest MRR when the ratio of LaOF in the polishing particles reaches $18 \%$. The lowest surface roughness $\left(R_{\mathrm{a}}\right)$ is achieved when the ratio of $\mathrm{LaOF}$ is around $10 \%$. Reasonable content of $\mathrm{LaOF}$ and few $\mathrm{LaF}_{3}$ are necessary to prepare the CLF compound powders with high polishing performance.

\section{Conflicts of interest}

There are no conflicts to declare.

\section{Acknowledgements}

This research was financially supported by the National Natural Science Foundation of China (Grant No. 51871045, 51471048) 
and the Basic Research Program of the Key Laboratory of Liaoning Province (No. LZ2015035).

\section{Notes and references}

1 C. W. Sun, H. Li and L. Q. Chen, Energy Environ. Sci., 2012, 5, 8475-8505.

2 C. W. Sun, J. Sun, G. L. Xiao, H. R. Zhang, X. P. Qiu, H. Li and L. Q. Chen, J. Phys. Chem. B, 2006, 110, 13445-13452.

3 C. W. Sun and L. Q. Chen, Eur. J. Inorg. Chem., 2009, 26, 3883-3887.

4 C. W. Sun, H. Li, Z. X. Wang, L. Q. Chen and X. J. Huang, Chem. Lett., 2004, 33, 662-663.

5 B. H. James and P. S. Shyama, J. Alloys Compd., 1994, 207208, 377-382.

6 H. J. Liu, Z. Y. Feng, X. W. Huang, Z. Q. Long, M. Wang, Y. F. Xiao and Y. K. Hou, J. Rare Earths, 2013, 31, 174-179.

7 P. H. Chen, C. P. Liu and C. Y. A. Tsao, Thin Solid Films, 2005, 479, 130-136.

8 Z. L. Wang and L. F. Cheng, J. Alloys Compd., 2014, 594, 167174.

9 X. S. Li, S. D. Huang and G. S. Yang, J. Rare Earths, 2004, 22, 302-306.

10 H. Gong, G. Pan, Z. Gu, C. L. Zou and Y. Liu, Tribol. Trans., 2014, 57, 366-372.

11 W. I. Kordonski and S. D. Jacobs, Int. J. Mod. Phys. B, 1996, 23-24, 2837-2848.
12 Y. W. Zhao, L. Chang and S. H. Kim, Wear, 2003, 254, 332339.

13 Z. F. Zhang, L. Yu, W. Liu and Z. Y. Song, Appl. Surf. Sci., 2010, 256, 3856-3861.

14 B. Gao, W. J. Zhai, Q. Zhai and M. Z. Zhuang, Appl. Surf. Sci., 2019, 484, 534-541.

15 H. Deng, K. Hosoya, Y. Imanishi, K. Endo and K. Yamamura, Electrochem. Commun., 2015, 52, 5-8.

16 J. Tichy, J. A. Levert and L. Shan, J. Electrochem. Soc., 1999, 146, 1523-1528.

17 Q. Xie, Y. Wang, B. Pan, H. Wang, W. Su and X. Wang, Catal. Commun., 2012, 27, 21-25.

18 N. Shehata, K. Meehan, M. Hudait and N. Jain, J. Nanopart. Res., 2012, 14, 1-5.

19 X. L. Wang, S. Z. Yi, E. W. Liang, Y. Y. Wu and Z. X. Fang, Adv. Mater. Res., 2013, 785-786, 480-483.

20 J. Lee, Q. Zhang and F. Saito, J. Am. Ceram. Soc., 2001, 84, 863-865.

21 D. S. Bae, B. Lim, B. I. Kim and K. S. Han, Mater. Lett., 2002, 56, 610-613.

22 W. Stoeckenius, J. H. Schulman and L. M. Prince, J. Phys. Chem., 1960, 169, 170-180.

23 W. Y. Wu, X. S. Li, J. Chen, G. S. Yang and G. F. Tu, J. Rare Earths, 2007, 25, 124-125.

24 L. M. Cook, J. Non-Cryst. Solids, 1990, 120, 152-157.

25 X. S. Li and G. S. Yang, J. Rare Earths, 2004, 22, 236-240. 